\title{
THERMOPHYSICAL CHARACTERIZATION OF IONOGELS OF ETHYLAMONIUM NITRATE AS ADVANCED ELECTROLYTES FOR ELECTROCHEMICAL DEVICES
}

\author{
J.J. Parajó*, M. Villanueva, J.R. Rodríguez, L.M. Varela, J. Salgado
}

\author{
NaFoMat Group. Departments of Applied Physics and Particles Physics. Universidade de Santiago de Compostela. Campus \\ Vida. 15782 Santiago. Spain \\ *e-mail: juanjose.parajo@usc.es
}

\begin{abstract}
Among the multiple applications of ionic liquids (ILs) and ionogels, electrolytes for electrochemical devices have a highlighted position. The interest in mixtures of ILs with alkaline metals salts has increased in the last years, since the presence of some electrochemically active species, is required for any electrochemical application of these designer solvents, e.g. in batteries.

Although physical characterization of common ILs, as ethylammonium nitrate (EAN), is extensively performed and published, thermophysical characterization of its ionogels is not yet well developed. In this work, the liquid range and thermal stability of ionogels of EAN and its mixtures with lithium nitrate $\left(\mathrm{LiNO}_{3}\right)$, an inorganic salt with a common anion, were measured.

Differential Scanning Calorimetry was employed to determine the melting and freezing temperatures, observing that the pure IL and mixture melt at $12{ }^{\circ} \mathrm{C}$ and $3{ }^{\circ} \mathrm{C}$, respectively, whereas no processes associated to the formation of a crystalline phase was observed for ionogels.

Moreover, using a thermogravimetric analyzer operating in dynamic and isothermal modes under dry air and nitrogen atmospheres, thermal stability analysis was performed. Pure IL and ionogels showed similar thermogravimetric curves characterized by a loss mass in a single step starting at 200 ${ }^{\circ} \mathrm{C}$ and finishing at $300^{\circ} \mathrm{C}$, approximately.
\end{abstract}

Keywords: Ionogel, Ionic liquid, DSC, TGA

\section{Introduction}

Beyond their traditional usage in fuel cell applications, the category of protic ionic liquids (PILs) has been recently signaled as a potential candidate for battery applications [1]. The presence of hydrogen donors and acceptors in the molecular species forming these ILs, associated to their specific synthesis, induces the formation of extensive H-bond networks that crucially determine their structural and transport properties [2,3]. The most studied PILs are those based on ammonium nitrates, specifically ethylammonium nitrate (EAN), which despite being the oldest known IL [4], and of having been extensively characterized in most of its properties [2,3,5], a full thermal and stability analysis in its gel form is still not performed. As it is well known, for many practical applications of any material, a complete characterization of any thermal transitions is essential. In 
case of gels of salts with electrochemical interest is necessary to know it useful temperature range, which includes the knowledge of the upper and lower limit temperatures.

In the present work, thermal analysis techniques were used to completely characterize possible thermal transitions and stability of pure IL, EAN ionogel and a doped EAN ionogel with lithium nitrate salt.

\section{Materials and methods}

\section{Chemical}

Main identification characteristics of selected ionic liquid, ethylammonium nitrate (EAN) are indicated in Table I. To obtain doped EAN ionogel, a lithium nitrate salt was used.

Table I. Chemical structure, identification number, molecular mass and purity of EAN and lithium nitrate salt.

\begin{tabular}{|c|c|c|c|}
\hline Chemical structure & CAS Identification number & Molecular mass & Purity \\
\hline & $2211386-6$ & $108.11 \mathrm{~g} / \mathrm{mol}$ & $>99 \%$ \\
\hline $\begin{array}{ll}\mathrm{O} & \\
\|_{+}^{N} & \mathrm{Li}\end{array}$ & $7790-69-4$ & $68.94 \mathrm{~g} / \mathrm{mol}$ & $>99 \%$ \\
\hline
\end{tabular}

Solutions of $\mathrm{EAN}+\mathrm{LiNO}_{3}$ have been performed by dissolving the salt into IL until saturation, in this case, the presents results are the corresponding to $\mathrm{EAN}+\mathrm{LiNO}_{3}$ at $0.1 \mathrm{~m}$.

Gelation process has been performed following Negre et al. methodology [6]. Essentially, a solid ionogel-based electrolyte was synthetized using two different sol-gel agents: TEOS (TetraEthyl OrthoSilicate) under acidic conditions (Trifluoroacetic Acid (TFA)) in a volumetric ratio TEOS:TFA 2:5. The reactants were mixed together under moderate stirring ( $300 \mathrm{rpm}$ ) at $40{ }^{\circ} \mathrm{C}$ during $18 \mathrm{~min}$. Finally, the addition of $60 \%$ by volume of ionic liquid in weight was done. The resulting solution was reserved in sealed containers and kept at room temperature for gelation during/for a week.

\section{Experimental section}

A differential scanning calorimeter DSC Q100 TA-Instruments with aluminum pans hermetically sealed was used to determine the possible different state transitions experimented by the EAN ionogel during heating and cooling cycles. Liquid nitrogen was used as coolant fluid. Liquid samples (3 - $5 \mathrm{mg}$ ) were subjected to four ramps, two in cooling and two in heating mode, with an isothermal step between them. The first two (one in heating and the other on cooling modes) were performed at heating rate of $10^{\circ} \mathrm{C} \mathrm{min}^{-1}$ to remove impurities and to erase the thermal history of the sample. The last two ramps were performed at lower heating rate, $5{ }^{\circ} \mathrm{C} \mathrm{min}^{-1}$, to increase the sensibility of the apparatus.

A thermogravimetric analyzer (TGA 7-Perkin Elmer) operating in dynamic and isothermal modes under nitrogen and air atmosphere was used to perform thermogravimetric analysis [7-10]. 
Samples of 3-5 mg were placed in an open platinum pan. Dynamic experiments were performed at temperatures from (100 to 800 ) ${ }^{\circ} \mathrm{C}$, with a heating rate of $10{ }^{\circ} \mathrm{C} \mathrm{min}^{-1}$ and a purge gas flow of $20 \mathrm{~cm}^{3}$ $\mathrm{min}^{-1}$. Each analysis was repeated three times. Determination procedures of onset and endset temperatures were described in previous papers [7-12]. Furthermore, isothermal TG analysis at temperatures lower than tonset, was used to determine the long-term thermal stability of ILs.

\section{Results}

\subsection{Phase transitions}

Figures 1 ( $a, b, c$ and d) shows the DSC curves on heating and cooling ramps of pure and doped EAN in liquid and gel forms, respectively

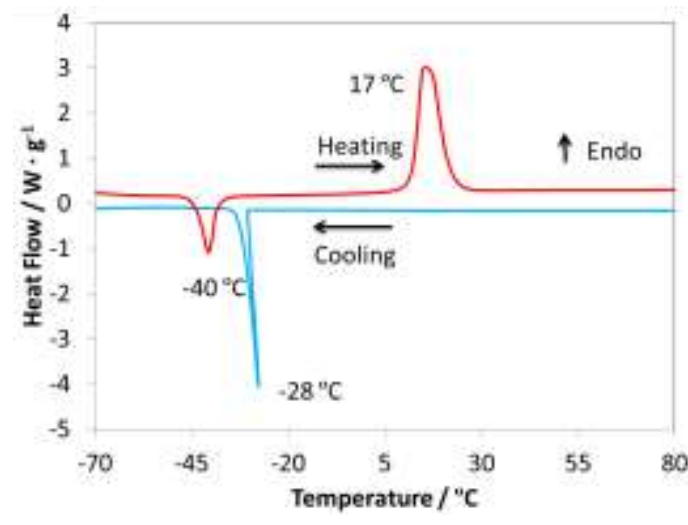

Fig 1a. DSC for pure EAN liquid

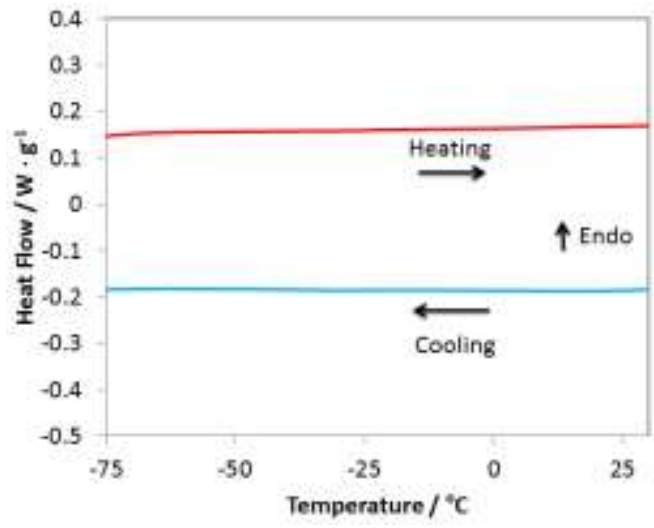

Fig 1c. DSC for EAN ionogel

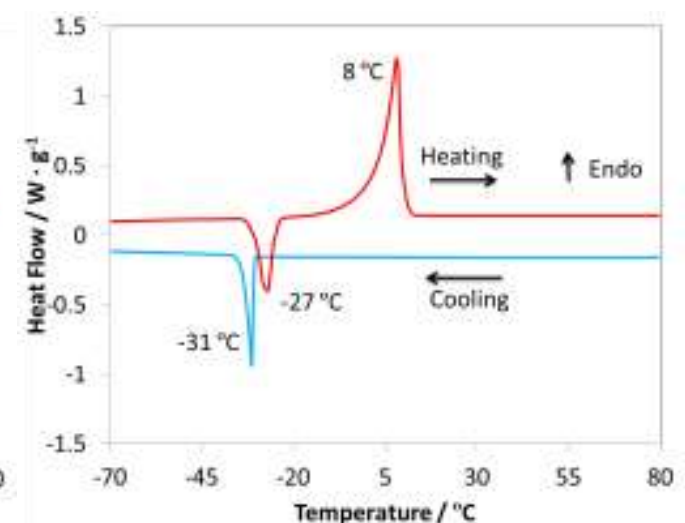

Fig 1b. DSC for doped EAN liquid

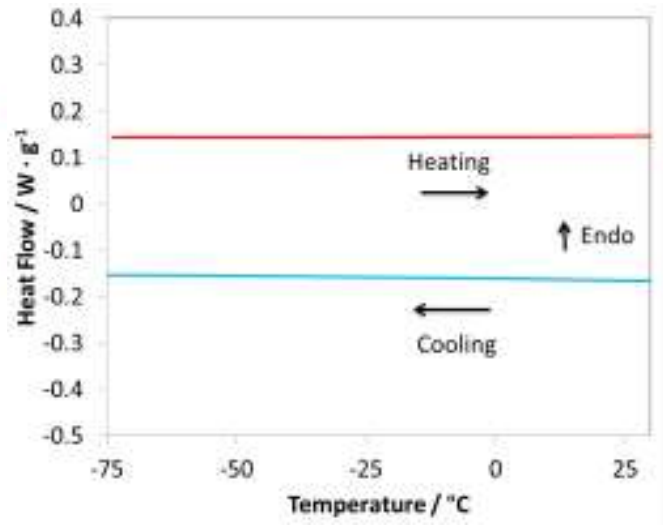

Fig 1d. DSC for doped EAN ionogel

Figure 1a presents a well-defined exothermic peak at $-28{ }^{\circ} \mathrm{C}$, with a heat evolved of $-82 \mathrm{~J} / \mathrm{g}$, can be observed on cooling ramp, and attributed to EAN crystallization. On the other hand, a melting peak (endothermic) at $17^{\circ} \mathrm{C}$ with $121 \mathrm{~J} / \mathrm{g}$, is shown in heating ramp. This difference between the enthalpies indicates that no complete crystallization took place on cooling the sample, i. e. amorphous phase is present in the sample at low temperatures, which shows a cold crystallization (exothermic) on heating ramp at $-40{ }^{\circ} \mathrm{C}$ with a heat associated of $-34 \mathrm{~J} / \mathrm{g}$.

As it can be seen in figure $1 \mathrm{~b}$, similar transitions were detected for doped EAN. Melting ( $8^{\circ} \mathrm{C}$ with 90 $\mathrm{J} / \mathrm{g}$ ) and crystallization $\left(-31^{\circ} \mathrm{C}\right.$ with $\left.-60 \mathrm{~J} / \mathrm{g}\right)$ were shifted to lower temperatures and cold 
crystallization $\left(-27^{\circ} \mathrm{C}\right.$ with $\left.-26 \mathrm{~J} / \mathrm{g}\right)$ to higher temperatures. However, different behaviors were observed for the EAN in gel forms, pure and doped ones. Figure 1c shows DSC scans for the EAN gel, for which no transitions were observed, that means that in the experimental temperature range there is no evidence of a crystalline structure. Same conclusion is obtained for doped EAN ionogel (figure 1d).

\subsection{Thermal stability}

The $t_{\text {onset, }}$ and $t_{\text {peak, }}$ measured from TG and DTG curves respectively, are presented in Table II. As it can be observed, there are no differences in the thermal behaviour under air and nitrogen atmospheres, unlike what has been observed for other imidazolium based ILs $[7,9,13]$. So, we can conclude that the thermal stability of EAN IL is not affected by the atmosphere.

Table II. Characteristic temperatures obtained from dynamic TG and DTG curves under air and nitrogen atmospheres for EAN liquid and gel.

\begin{tabular}{|c|c|c|c|c|}
\hline & \multicolumn{2}{|c|}{$t_{\text {onset }} /{ }^{\circ} \mathrm{C}$} & \multicolumn{2}{c|}{$t_{\text {peak }} /{ }^{\circ} \mathrm{C}$} \\
\hline & Air & $\mathbf{N}_{2}$ & Air & $\mathbf{N}_{2}$ \\
\hline EAN liquid & 249 & 247 & 265 & 266 \\
\hline Doped EAN liquid & --- & 239 & --- & 252 \\
\hline EAN ionogel & 248 & 253 & 264 & 268 \\
\hline Doped EAN ionogel & 207 & 213 & 231 & 231 \\
\hline
\end{tabular}

On the other hand, doped and gel samples do not present important variation on thermal stability with regard to the pure IL, only in the case of doped ionogel an small decrease on onset temperature was observed, but this reduction do not affect its possible use as electrolyte.

As example, figure 2 presents the dynamic TG and DTG curves for the doped EAN ionogel obtained at $10{ }^{\circ} \mathrm{C} / \mathrm{min}$ in air and in nitrogen atmospheres. As it can be observed, the shapes of TG and DTG curves obtained in air and in nitrogen atmospheres are similar. In both cases, the degradation of the sample initiates at $150^{\circ} \mathrm{C}$, and it takes place in a simple step and it is completed at approximately 200 ${ }^{\circ} \mathrm{C}$. 


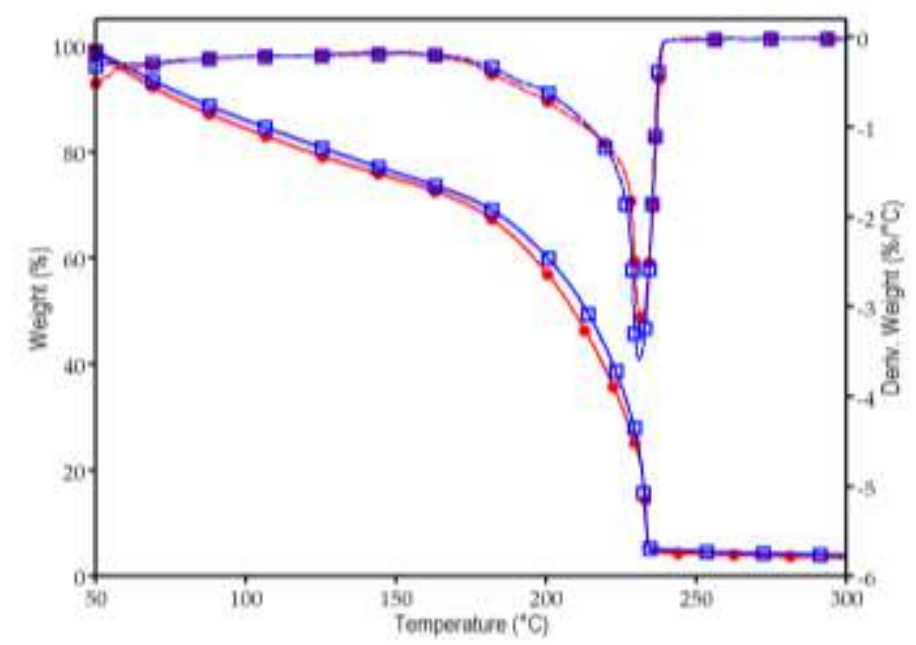

Fig 2. TG and DTG curves for doped EAN ionogel in nitrogen (blue) and air atmosphere (red)

To complete this study, isothermal scans at six temperatures lower than onset were performed in nitrogen atmosphere. Figure 3 shows these scans.

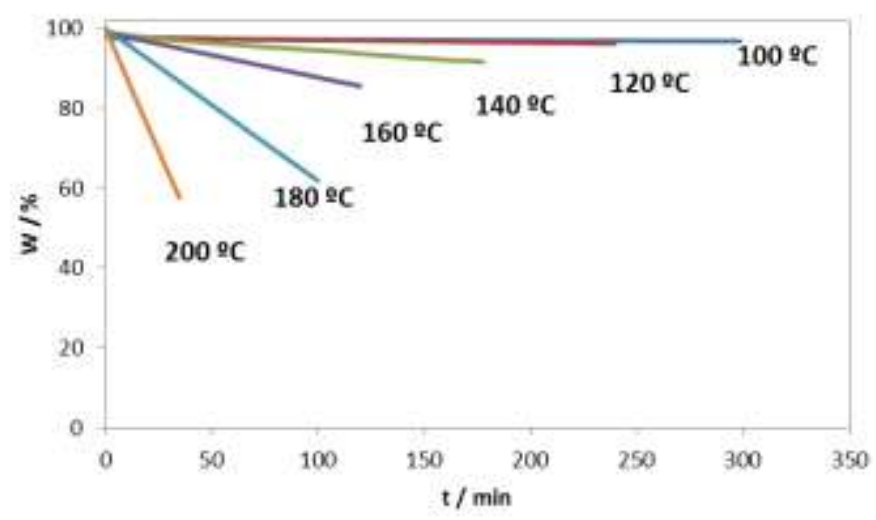

Figure 3. Isothermal curves of pure EAN liquid in $\mathrm{N}_{2}$ atmosphere

\section{Conclusions}

The main conclusions of this work are the following:

No evidences of crystalline behavior has been observed in DSC curves of ionogel of EAN, pure and doped.

Similar thermal stability has been obtained for pure EAN, doped and gel samples.

\section{Acknowledgments}

This work was supported by Spanish Ministry of Economy and Competitiveness and FEDER Program through the CTQ2011-23925 and MAT2014-57943-C3-1-P projects as well as by Xunta de 
Galicia through the EM2013/031, AGRUP2015/11 and GRC ED431C 2016/001 projects and the Galician Network of Ionic Liquids (ReGaLIs) ED431D 2017/06.

\section{References}

[1] S. Menne, R.S. Kühnel, A. Balducci, Electrochim. Acta 90 (2013) 641.

[2] T.L. Greaves, C.J. Drummond, Chemical Reviews 108 (2008) 206.

[3] T.L. Greaves, C.J. Drummond, Chemical Reviews 115 (2015) 11379.

[4] P. Walden, Chem. Zentralbl 85 (1914) 1800.

[5] S.B. Capelo, T. Méndez-Morales, J. Carrete, E. López Lago, J. Vila, O. Cabeza, J.R. Rodríguez, M. Turmine, L.M. Varela, The Journal of Physical Chemistry B 116 (2012) 11302.

[6] L. Negre, B. Daffos, V. Turq, P.L. Taberna, P. Simon, Electrochim. Acta 206 (2016) 490.

[7] J.J. Parajó, T. Teijeira, J. Fernández, J. Salgado, M. Villanueva, J. Chem. Thermodynamics 112 (2017) 105.

[8] J. Salgado, J.J. Parajó, J. Fernández, M. Villanueva, J. Chem. Thermodynamics 74 (2014) 51.

[9] J. Salgado, M. Villanueva, J.J. Parajó, J. Fernández, J. Chem. Thermodynamics 65 (2013) 184.

[10] M. Villanueva, J.J. Parajó, P.B. Sánchez, J. García, J. Salgado, J. Chem. Thermodynamics 91 (2015) 127.

[11] J.J. Parajó, M. Villanueva, I. Otero, J. Fernández, J. Salgado, J. Chem. Thermodynamics 116 (2018) 185.

[12] M. Villanueva, A. Coronas, J. García, J. Salgado, Ind. Eng. Chem. Res. 52 (2013) 15718.

[13] M. Villanueva, J. Proupín, J. Rodríguez-Añón, L. Fraga-Grueiro, J. Salgado, N. Barros, J. Therm. Anal. Calorim. 104 (2011) 61. 